Article

\title{
Dynamic Exergy Analysis for the Thermal Storage Optimization of the Building Envelope
}

\author{
Valentina Bonetti ${ }^{1, *}$ and Georgios Kokogiannakis ${ }^{2}$ \\ 1 Energy Systems Research Unit (ESRU), University of Strathclyde, Glasgow G1 1XJ, UK \\ 2 Sustainable Buildings Research Centre (SBRC), University of Wollongong, Wollongong, NSW 2500, \\ Australia; gkg@uow.edu.au \\ * Correspondence: valentina.bonetti@strath.ac.uk; Tel.: +44-(0)141-548-3986 \\ Academic Editors: Kondo-Francois Aguey-Zinsou, Da-Wei Wang and Yun-Hau Ng \\ Received: 1 September 2016; Accepted: 22 December 2016; Published: 13 January 2017
}

\begin{abstract}
As a measure of energy "quality", exergy is meaningful for comparing the potential for thermal storage. Systems containing the same amount of energy could have considerably different capabilities in matching a demand profile, and exergy measures this difference. Exergy stored in the envelope of buildings is central in sustainability because the environment could be an unlimited source of energy if its interaction with the envelope is optimised for maintaining the indoor conditions within comfort ranges. Since the occurring phenomena are highly fluctuating, a dynamic exergy analysis is required; however, dynamic exergy modelling is complex and has not hitherto been implemented in building simulation tools. Simplified energy and exergy assessments are presented for a case study in which thermal storage determines the performance of seven different wall types for utilising nocturnal ventilation as a passive cooling strategy. Hourly temperatures within the walls are obtained with the ESP-r software in free-floating operation and are used to assess the envelope exergy storage capacity. The results for the most suitable wall types were different between the exergy analysis and the more traditional energy performance indicators. The exergy method is an effective technique for selecting the construction type that results in the most favourable free-floating conditions through the analysed passive strategy.
\end{abstract}

Keywords: dynamic exergy analysis; building envelope; energy storage

\section{Introduction}

Exergy is a state function that combines the first and second law of thermodynamics through a reference environment. The strong dependency of exergy from the defined reference creates a "co-property" of the system and the environment [1] and enables a quantification of energy quality, measured as "the maximum theoretical useful work obtainable as the system interacts to equilibrium, heat transfer occurring with the environment only" [2]. A simple way to obtain exergy fluxes is to apply "quality factors" $q f$ as conversion factors of the energy fluxes. For example, in the case of a conductive heat transfer $Q$ occurring at a constant $T$, if the reference environment has temperature $T_{0}$, the associated exergy transfer $B$ is directly derived from the Carnot efficiency as:

$$
B(Q)=q f \cdot Q=\left(1-\frac{T_{0}}{T}\right) \cdot Q,
$$

Other types of energy exchanges have higher quality factors, which means that a greater portion of the energy flux can be converted into useful work (for instance, electricity has a quality factor of one).

Exergy analysis represents an established technique in the process optimization of many engineering fields, for example of thermal power plants, and as thoroughly explained in the IEA 
Annex 49 report [3], it is a potentially useful technique to also promote a more rational use of energy resources in the built environment. The quality of the energy contained in a comfortable room is fairly low, because the indoor temperatures are around $20^{\circ} \mathrm{C}$, which corresponds to a quality factor of $7 \%$ if the reference temperature is $0{ }^{\circ} \mathrm{C}$. However, in this case, the overall energy demand of the building is often satisfied with a much higher quality source of energy supply.

Understanding and quantifying energy quality (exergy) is crucial for a rational use of limited resources, where supplies and demands are properly matched to reduce waste. However, the application of the exergy approach to building design is still very limited. Major obstacles for the dissemination of building exergy analysis are its complexity, the controversial definition of the reference state [4] discussed in Section 2.2.3 and a lack of dynamic exergy simulation tools (some of which are described in [3]). Furthermore, the building envelope, which is the last element of the energy chain shown in Figure 1, is not considered in detail, to the authors' best knowledge, in any guideline or case study in the literature.

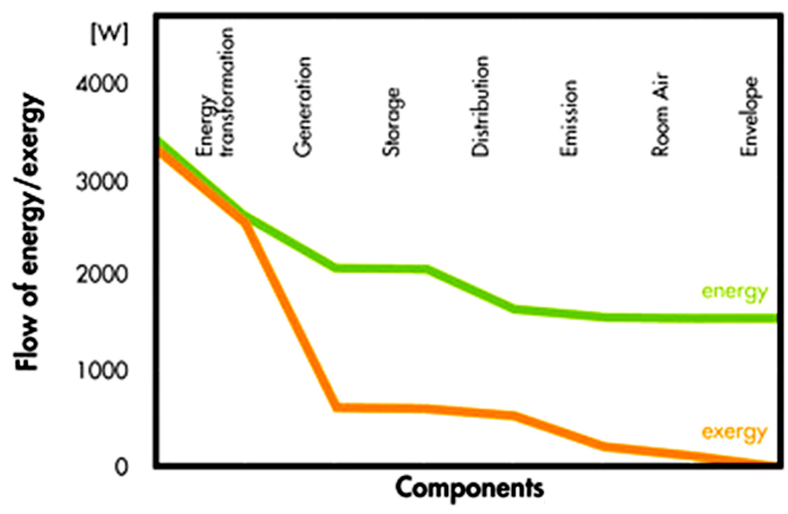

Figure 1. Energy and exergy flux through the building energy chain (adapted from [3]) with permission from the Fraunhofer Institute for Building Physics, 2011.

On the other hand, the interaction between buildings and their surrounding environment is often not optimal. One common problem is constituted by the summer performance of building constructions located in climates with hot days and relatively low nocturnal temperatures (like the Mediterranean). The role of thermal mass in lowering the cooling load of buildings is largely documented (e.g., in [5-8]), but not systematically and quantitatively acknowledged in current practice. The inner part of the envelope of modern buildings is generally not designed to absorb and release all of the internal and solar gains in a daily cycle, and air-conditioning is the usual solution to address the occurrences of overheating. Low nocturnal outdoor temperatures are barely exploited as they were in traditional architecture.

This research explores the exergy approach as a tool to optimise the interactions of the building envelope with its environment, before any HVAC system is introduced. The theoretical framework for the exergy calculations is developed in Section 2.2. Seven different high-performance wall types, described in Section 2.3.3, are compared on the basis of energy and exergy assessments to support the design process of a case study residential building in Rome (Italy). An energy ranking is based on the dynamic performance indicators decrement factor $f$ and time lag $\tau$, as per common practice (Section 2.1). Exergy considerations suggest the exploitation of nocturnal natural ventilation as a passive cooling strategy, and therefore, different rates of nocturnal ventilation are investigated. Simplified exergy calculations, based on hourly results obtained from the dynamic energy software ESP-r [9], are conducted through the objective function defined in Section 2.2.4 for a limited portion of the envelope on a critical summer day and used to rank the different walls in terms of their exergy storage capability. The energy and exergy rankings are then compared, with the support of the maximum indoor temperatures extracted from the dynamic energy simulations. 


\section{Methods and Materials}

This research is focused on the potential for thermal storage in the envelope. The guidance provided by the energy analysis typically performed to select the envelope during the design phase, discussed in Section 2.1, is compared to the support offered by a tailored exergy assessment (presented in Section 2.2) for the case study described in Section 2.3 representing a common example in the Mediterranean climate.

\subsection{Energy Analysis}

In a typical workflow, the energy analysis in support of the design process is conducted according to the methods recommended in the official Italian guidelines [10] (described in [11]) and [12], as derived from European directives. The following indicators are commonly used:

- $\quad$ steady-state energy performance:

- U-value $\left(U ;\left(\mathrm{W} / \mathrm{m}^{2} \mathrm{~K}\right)\right)$

- $\quad$ mass per area $\left(M_{a} ;\left(\mathrm{kg} / \mathrm{m}^{2}\right)\right)$

- thermal capacity per area $\left(C_{t a} ;\left(\mathrm{kJ} / \mathrm{m}^{2} \mathrm{~K}\right)\right)$

- monthly energy demand data

- dynamic energy performance:

- $\quad$ decrement factor $(f)$

- $\quad$ time lag $(\tau ;(h))$

In a few cases, further calculations are performed, such as:

- dynamic energy performance:

- $\quad$ indoor admittance modulus $\left(Y_{i i}\right.$ modulus; $\left.\left(\mathrm{W} / \mathrm{m}^{2} \mathrm{~K}\right)\right)$

- $\quad$ indoor admittance phase $\left(Y_{i i}\right.$ phase; $\left.(\mathrm{h})\right)$

Simulation data (such as temperatures and consumptions) from a dynamic energy software are rarely obtained because they are not required by Italian building regulations.

In this study, seven different realistic construction types, detailed in Appendix A, are compared on the basis of the envelope indicators generally used in a preliminary energy assessment (U-value, decrement factor, time lag, mass per area, static thermal capacity, indoor admittance). Thereafter, the different types are ranked according to the following indicators that are mainly considered for envelope selection during the summer performance evaluations: decrement factor $f$ and time lag $\tau$.

\subsection{Exergy Analysis}

\subsubsection{The Exergy Balance}

The theoretical framework of this study, as extracted and adapted by the proposal of Pons [4] considers a simplified system working as storage and where the boundaries of the following three fluxes occur in a cyclic process of charging and discharging: a power input $p$, a useful effect $u$, for instance heat subtraction, and an energy exchange with the environment env. The instantaneous formulations of the first and second law of thermodynamics, in terms of energy $(e)$ and entropy $(s)$ rates, are:

$$
\left\{\begin{array}{l}
e_{p}+e_{u}+e_{e n v}=\dot{E} \\
s_{p}+s_{u}+s_{e n v}+\dot{P}_{s}=\dot{S}
\end{array}\right.
$$


in which $\dot{E}$ and $\dot{S}$ represent the rate of energy and entropy stored in the system, respectively (null for stationary processes), and $\dot{P}_{S}$ the instantaneous production of entropy. If the ratio of entropy-energy (which is often, but not always, approximately constant) of the generic flux $x$ is called $r_{x}=s_{x} / e_{x}$, the system (2) becomes:

$$
\left\{\begin{array}{l}
e_{p}+e_{u}+e_{e n v}=\dot{E} \\
r_{p} e_{p}+r_{u} e_{u}+r_{e n v} e_{e n v}+\dot{P}_{s}=\dot{S}
\end{array}\right.
$$

For example, for fluxes like work or electricity, the associated entropy is null, and thus, $r_{x}=0$; for a constant-temperature, heat flow (transferred through a boundary at $T_{x}$ ) is $r_{x}=1 / T_{x}$.

Exergy is the linear combination of energy and entropy through a constant reference temperature $T_{0}$; the instantaneous exergy balance is thus obtained by multiplying the second equation of (3) by $T_{0}$ and then subtracting the result from the first equation of (3):

$$
e_{p}\left(1-T_{0} r_{p}\right)+e_{u}\left(1-T_{0} r_{u}\right)+e_{e n v}\left(1-T_{0} r_{e n v}\right)=\left(\dot{E}-T_{0} \dot{S}\right)+T_{0} \dot{P}_{s} .
$$

The energy terms $e$ are multiplied by the term $\left(1-T_{0} r_{x}\right)$, the so-called "quality factor", to obtain exergy flows on the left-hand side, while the right-hand side represents the system state variation, which is composed of the exergy storage and the exergy losses due to irreversibilities. Introducing $B$ as the notation for exergy and $b$ for exergy flow rates, Equation (4) becomes:

$$
b_{p}+b_{u}+b_{\text {env }}=\dot{B}+\text { irreversibilities. }
$$

where $\dot{B}$ is the exergy variation rate of the system. Time integration in the generic interval $\left[0, t^{*}\right]$ leads to:

$$
E_{p}\left(1-T_{0} r_{p}\right)+E_{u}\left(1-T_{0} r_{u}\right)+\int_{0}^{t^{*}} e_{e n v}\left(1-T_{0} r_{e n v}\right) d t-\int_{0}^{t^{*}} T_{0} \dot{P}_{s} d t=\int_{0}^{t^{*}} \dot{E} d t-T_{0} \int_{0}^{t^{*}} \dot{S} d t .
$$

in which $r_{p}$ and $r_{u}$ are considered constant, but $r_{e n v}$, and thus, the environmental quality factor $1-T_{0} r_{\text {env }}$ is potentially variable, which means that the exergy extracted from the environment can have a fluctuating quality.

In a cyclic process, exergy content variations (the right-hand side of Equation (6)) are null after a period or negligible for a non-perfect cycle. The exergy balance over a cycle is therefore:

$$
E_{p}\left(1-T_{0} r_{p}\right)+E_{u}\left(1-T_{0} r_{u}\right)+\oint e_{e n v}\left(1-T_{0} r_{e n v}\right) d t \approx \oint T_{0} \dot{P}_{s} d t
$$

The first term on the left side of Equation (7) is the exergy input from the generic power source (its main distinctive feature being a non-zero monetary value); the second term represents the useful effect (for example, the coverage of the building thermal demand); and the third term is the exergy exchanged with the environment; on the other side, the exergy is destroyed by irreversibility. In synthesis, Equation (7) can be written as:

$$
B_{p}+B_{\text {env }}+B_{u} \approx \text { irreversibilities. }
$$

\subsubsection{The Exergy Balance Applied to the Building Envelope}

In the case of the building envelope, the useful effect $B_{u}$ is the coverage of heating or cooling loads and, thus, the satisfaction of the corresponding building "exergy demand" $\left(B_{\text {demand }}\right)$, of the opposite sign. The balance (8) can therefore be written as:

$$
B_{p}+B_{\text {env }} \approx B_{\text {demand }}+\text { irreversibilities }
$$


The complication of the balancing Equation (9) when applied to the building envelope is that $B_{\text {env }}$ and $B_{\text {demand }}$ are not distinctly distinguished a priori: the spontaneous interaction with the environment, together with internal loads, is the cause of the exergy demand $B_{\text {demand }}$, which therefore has the same provenance of the term $B_{\text {env }}$. However, the reason for having two separate contributions lies in the different steps in which the design process can be subdivided:

1. envelope exergy demand $\left(B_{\text {demand }}\right)$ reduction

2. exergy extraction from the environment $\left(B_{\text {env }}\right)$

3. power input and irreversibility $\left(\oint T_{0} \dot{P}_{s}\right)$ optimization

The final aim is to reduce the need of the power exergy input $B_{p}$. The first step is the application of classical conservation measures, for example appropriate envelope insulation or shading devices, in order to achieve indoor "free-floating" conditions (which means in absence of HVAC systems) that are as near as possible to thermal comfort. In many cases, thermal comfort is not achieved with simple measures, and an exergy input is still required. The second step tries to answer the question: how much of the demanded exergy can be actually extracted by the same surrounding environment and how? This second step, which is the focus of the present study, analyses the free-floating behaviour of the building in depth and precedes any decision about the power source possibly needed to achieve thermal comfort. The last step, if required, involves the design of power input systems and their optimisation, which deserves a deeper discussion, and it is not included in this study. It is worth noting that maximising the exergy extraction from the environment does not coincide with irreversibility minimisation and, on the contrary, can even lead to a more irreversible system; however, buildings are not machines, and irreversibility and sustainability are not necessarily counterposed if carbon-based sources are not involved. This discussion is out of the reach of the present investigation and constitutes the focus of further research.

\subsubsection{The Reference Temperature $T_{0}$}

The reference temperature for dynamic exergy analysis is a highly controversial issue, and no consensus has yet been reached on the most suitable choice. Pons [4] demonstrated analytically that a variable reference state corresponding to the outdoor air temperature $T_{\text {air }}$ (used by the vast majority of authors) leads to a path-dependent "exergy", which is no longer a function of state, and thus, it cannot be used as such. A comparison between variable and fixed references used for the dynamic exergy analysis of this study pointed out that the fluctuating value of the external temperature brings perplexing results about exergy storage, as opposed to the ones obtained with a fixed reference, which are sound and easy to interpret.

In this research, the constant value $T_{0}=26^{\circ} \mathrm{C}$ is therefore used as the reference temperature. Pons [4] suggests the use of the "most favourable" temperature for the considered process that is available in the surrounding environment. For a standard cooling system, the most favourable choice would be the minimum value of the ambient air temperature $T_{\text {air }}$ in the assessed period $\left(T_{0}=\min \left(T_{\text {air }}(t)\right)\right)$. However, the aim is to minimise the envelope exergy demand and consequently to maximise exergy harvesting from the environment whenever possible.

During cooling periods, the upper limit of the comfort zone represents a threshold, and all energy flows occurring at a lower temperature can be considered useful to achieve thermal comfort, proportionally to their quality factors. Consequently, a reference temperature defined as the comfort-zone upper limit $\left(26^{\circ} \mathrm{C}\right.$ for the case study climate) makes the meaning of "warm" and "cool" exergy clear: a cool exergy input decreases the exergy cooling demand; a warm exergy input causes an increase. Temperatures above $T_{0}$ represent "warm" exergy and below $T_{0}$ "cool" exergy, as defined by Shukuya [13]. The actual availability of the reference state in the surrounding environment is widely considered in the exergy literature as a necessary feature for a proper reference-state definition. The reference $T_{0}=26{ }^{\circ} \mathrm{C}$ is within the outdoor temperature range in any cycle of the investigated 
period of this study, as can be observed in Figure 2, which reports the ambient air temperatures for the period 17-20 of August of the climate file.

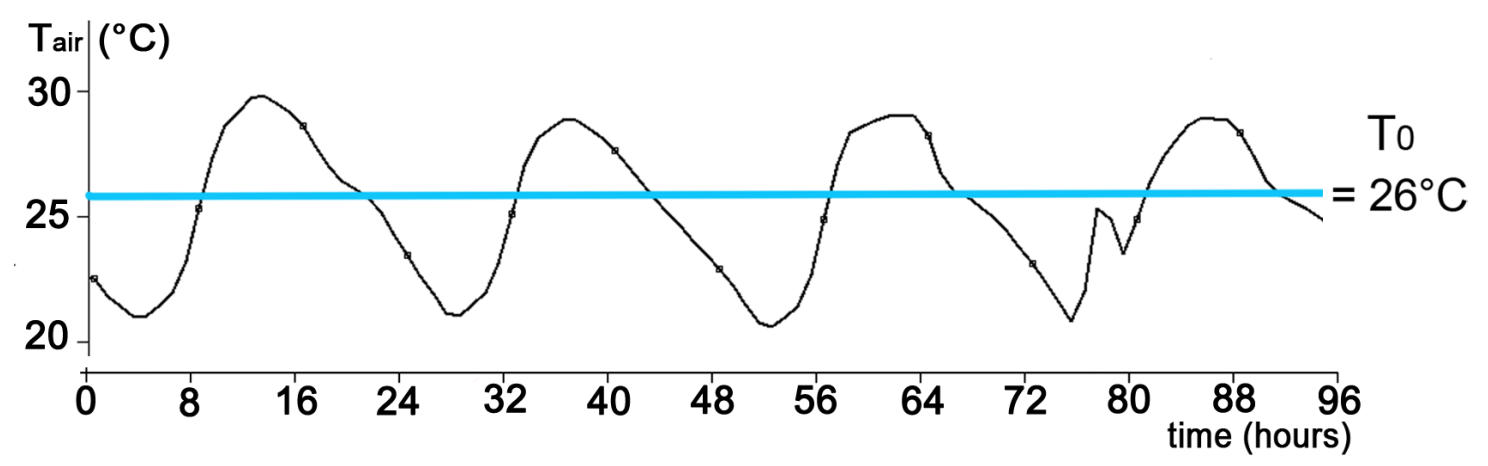

Figure 2. Outdoor air temperature $T_{\text {air }}$ trend (Rome) and const $T_{0}$ in case study days (17-20 August).

\subsubsection{A Simplified Model for Nocturnal Ventilation as a Cooling Strategy}

A detailed analysis with a dynamic exergy simulator would be needed to assess every term of the exergy balance (7) and gain a deeper insight into the interactions between the building and its environment, but no dynamic exergy tools are directly available yet. However, a simpler model, focused on the most relevant phenomena in the investigated case, can be used to understand the potentialities of exergy analysis in this context, and it is thus adopted.

The aim of the proposed analysis is to provide support to the second design step mentioned in Section 2.2.2, the enhancement of the extraction of useful exergy from the surrounding environment. The easiest and potentially lease expensive option is considered as a simple example for demonstrating the design process: the environmental exergy $b_{e n v}$ is extracted only from the outdoor air by means of nocturnal natural ventilation and stored in the building envelope, neglecting all other possibilities (e.g., an exchange with the ground).

The typical summer cycle can be divided into two main periods: day and night. During the day, the exergy $B_{u}$ from cooling loads is adsorbed by the wall interior surfaces until the maximum storage point (left part of Figure 3); then, the indoor temperature tends to rise, and a power input $B_{p}$ is needed to maintain comfort. During the night, when the outdoor air temperature is below the comfort setpoint (right part of Figure 3), heat can be released from wall interior surfaces to fresh air introduced inside the thermal zone (which corresponds to the exergy $B_{\text {env }}$ extracted from the ventilation air); a power input $B_{p}$ is generally not needed in this phase, but could be requested in some cases (for example, if the time constant of the distribution system is high or in case of off-peak demand strategies). The power source selection and its distribution system, symbolically represented by embedded pipes in Figure 3, are not discussed in this study, since they constitute the focus of the third design step.

In this simplified case, the useful effect $B_{u}$ of Equation (8) is subtracting the cooling demand $E_{\text {demand }}$ at a generic demand temperature $T_{\text {demand }}$, which depends on the distribution system adopted; the daily exergy balance therefore becomes:

$$
E_{p}\left(1-T_{0} r_{p}\right)+\oint q_{\text {air }}\left(1-\frac{T_{0}}{T_{\text {air }}}\right) d t \approx E_{\text {demand }}\left(1-\frac{T_{0}}{T_{\text {demand }}}\right)+\oint T_{0} \dot{P}_{s} d t
$$

in which the cooling loads representing an exergy output (negative) become a positive exergy demand on the right-hand side, and the environmental resource $e n v$ under investigation is air $\left(e_{e n v}=q_{\text {air }}\right.$ : heat exchanged by convection at temperature $T_{\text {air }} ; r_{\text {env }}=1 / T_{\text {air }}$ ). The 24-h cycle is split into two parts, cool-exergy storage charging (at night, zone unoccupied) and discharging (daytime, zone occupied).

The main hypotheses are:

- the envelope $\mathrm{U}$-value is low $\left(\leq 0.3 \mathrm{~W} / \mathrm{m}^{2} \mathrm{~K}\right.$ as an indicative example) 
- decrement factor and time lag are such that the transmission through the wall is negligible when considering storage effects

- the analysed thermal zone is unoccupied during nocturnal periods of natural ventilation (comfort requirements can thus be relaxed, and air velocity can exceed comfort limits)

- the indoor temperature can be maintained at outdoor $T_{\text {air }}$ through high-rate ventilation (10 air changes per hour $(\mathrm{ACH})$ or more) if needed.
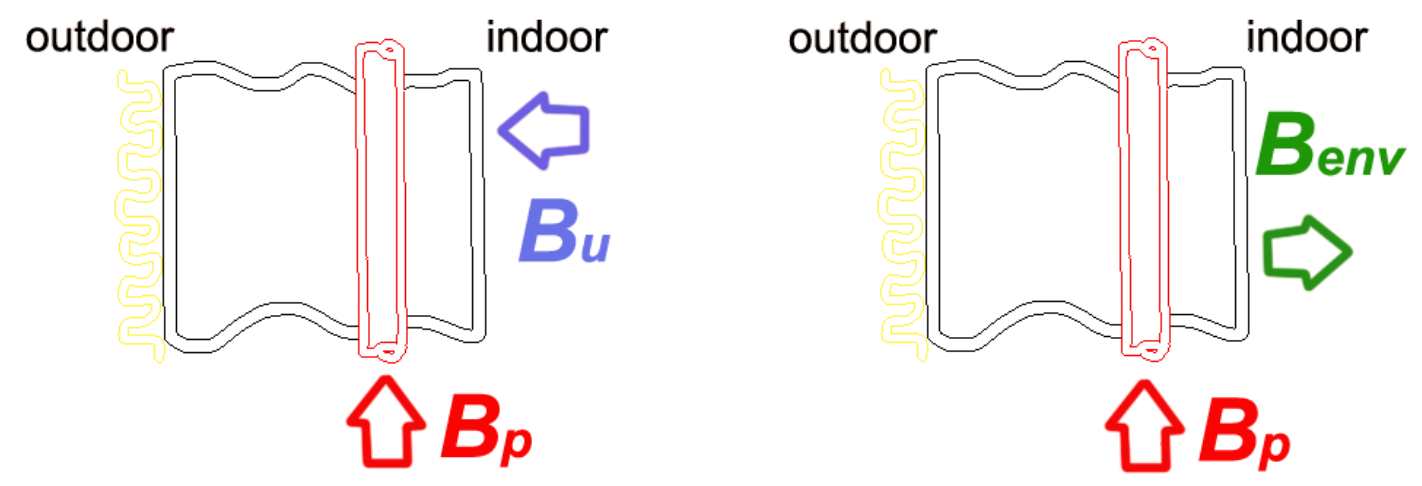

Figure 3. Envelope simplified fluxes: during the summer day, the useful effect $B_{u}$ is represented by the absorption of internal gains (on the left), whilst during the night, $B_{\text {env }}$ is released to the external air by means of increased ventilation (on the right). The power input $B_{p}$, if needed, is delivered by the distribution system (here represented by the embedded red pipe).

The most relevant phenomena become the daytime absorption of internal and solar gains and the nocturnal release of the energy accumulated in the thermal mass. The simplified model consists of a closed system whose boundaries are the middle section of the wall (considered as completely insulated from the exterior) and a parallel layer inside the thermal zone, where the temperature reaches the room value.

The second design step consists of maximising the exergy extracted from ambient air when its temperature is sufficiently low. In this case, the power input exergy required to facilitate the exchange should be null or lower than $B_{\text {air }}$. This translates in an objective function, the cool exergy of external air, to be maximised over the night (when $T_{\text {air }}<T_{0}$ ):

$$
B_{\text {air }}=\oint q_{\text {air }}\left(1-\frac{T_{0}}{T_{\text {air }}}\right) d t
$$

In this simplified case, the objective Function (11) is calculated for a significant sample of the seven envelopes, located at the east wall of the living room, where the most critical temperatures are reached during the typical hot day. The objective Function (11) is used as a ranking criteria because the aim of the second design step, the focus of this investigation as described in Section 2.2.2, is the maximisation of the useful exergy extraction from the environment.

\subsection{Case Study}

The optimisation of the envelope behaviour during the summer period constitutes a common issue in the Mediterranean climate, often neglected in the recent past in favour of the prominent role of HVAC systems. Once the possible construction options are declared suitable for the winter, which mainly requires a low U-value because the winter behaviour is not very far from a steady-state situation in this climate, the comparison of their performance in the highly-dynamic summer conditions is less trivial. In temperate climates, the growing use of air-conditioning during the summer represents a contemporary problem, especially in recent and new well-insulated buildings. The dynamic nature of the envelope performance is nowadays generally considered by the decrement factor $f$ and the time 
$\operatorname{lag} \tau$, but these indicators only describe the attenuation of external temperatures. Other effects, such as the role of the inner layers of walls in dealing with internal loads, are often neglected despite their potential impact in cooling strategies.

The optimisation problem of finding the most suitable envelope for the summer period of a particular case in a temperate location is investigated through dynamic energy indices and free-floating exergy assessments of a countryside house in a Mediterranean climate (Rome, Italy).

\subsubsection{Energy Calculations}

The thermal performance of the envelopes is calculated according to the European Standard EN ISO 13786 (the Italian version is [12]) by means of the software developed by Ursini Casalena ("UNI EN ISO 13786-Ver 2.2" [14], released under the CC BY-NC-SA 2.5 licence). The indicators specified in Section 2.1 are evaluated and reported in Section 3.1.

However, detailed dynamic energy calculations underpin the simplified exergy analysis and are therefore carried out for the case study. The simulations are conducted in free-floating operation mode, and therefore, they do not provide energy consumption figures and are not directly used as energy design guidance. Buildings present a series of complex and dynamic interactions between different forms of heat, momentum and mass transfer. During an investigation phase, a detailed and flexible simulation engine is required to model what is needed for the specific research at the necessary level of detail. In our study of the envelope exergy analysis, temperature values inside the wall layers are needed.

The software ESP-r [9] (distributed under a GNU GPL licence) transparently provides temperature values within each construction layer, which are not often, if at all, obtainable with other dynamic simulation software. The dynamic energy simulations, on which the exergy analysis is based, are therefore performed with the ESP-r software.

ESP-r adopts a finite volume approach: conservation equations for energy, mass and momentum are applied to control volumes around each node of the model [15]. The open-source nature of the software makes it also possible to think about future exergy-analysis integrated modules.

The weather file used for the simulations is included in the ESP-r standard database [16] (named "ita_ rome_ iwec") and contains annual data relative to the year 1987, Rome (coord.41.8 N 2.77 W).

Seven high-performance wall types, almost similar in static terms (U-value), decrement factor $f$ and time lag $\tau$, but with different thermal masses, as described in Section 2.3.3, are tested on a critical summer day, 17 August of the weather file) for the case study. Every simulation in this study is operated in free-floating mode, without power input, and the indoor conditions are not constrained by any HVAC system. The simulations are conducted at different levels of nocturnal ventilation, from midnight-8 a.m. and 10 p.m.-midnight: $0.5 \mathrm{ACH}$ (considered the minimum level for a good indoor air quality, even if Italian building regulation allows for an average value of $0.3 \mathrm{ACH}$ ), $5 \mathrm{ACH}$, $10 \mathrm{ACH}$ and a fictitious value of $100 \mathrm{ACH}$, which has no practical meaning in conventional ventilation methods, but provides the asymptotic value of the performance. The exergy analysis is then based on the results obtained with a nocturnal ventilation of $10 \mathrm{ACH}$, which can be reasonably achieved with natural ventilation. No mechanical ventilation is considered in this study. If mechanical ventilation is necessary or opportune, its energy and exergy consumption should be obviously considered in the comparison between nocturnal ventilation and other cooling strategies.

\subsubsection{Building}

The case study is a typical residential building in the countryside near Rome; a standard geometry and a set of ordinary casual gains are modelled with the ESP-r dynamic software (Figure 4). Since the attention is on the design process, the particular case is not significant. The east facade selected for the exergy analysis is highlighted in Figure 5, and the casual heat gains for both thermal zones are reported in Figures 6 and 7. The building has a surface-volume ratio of 0.64; the outside surface area is $263.4 \mathrm{~m}^{2}, 53 \%$ of which is vertical; and the volume is $411 \mathrm{~m}^{3}$. 


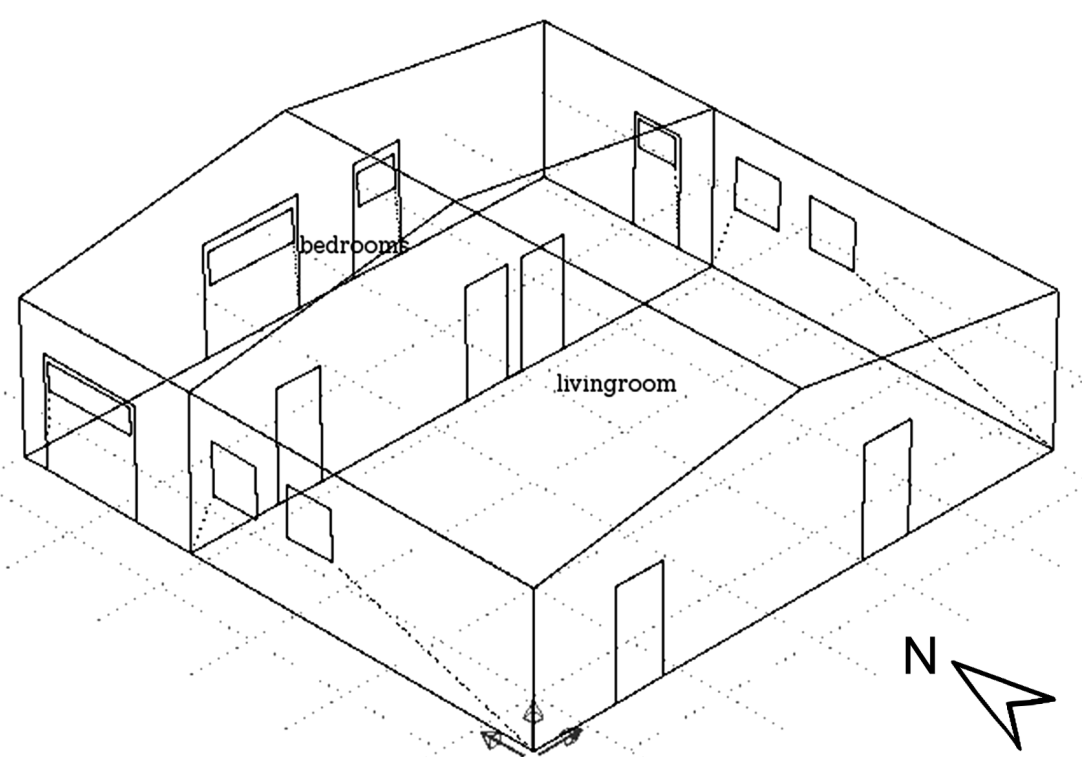

Figure 4. Building model in ESP-r: envelope geometry and orientation.
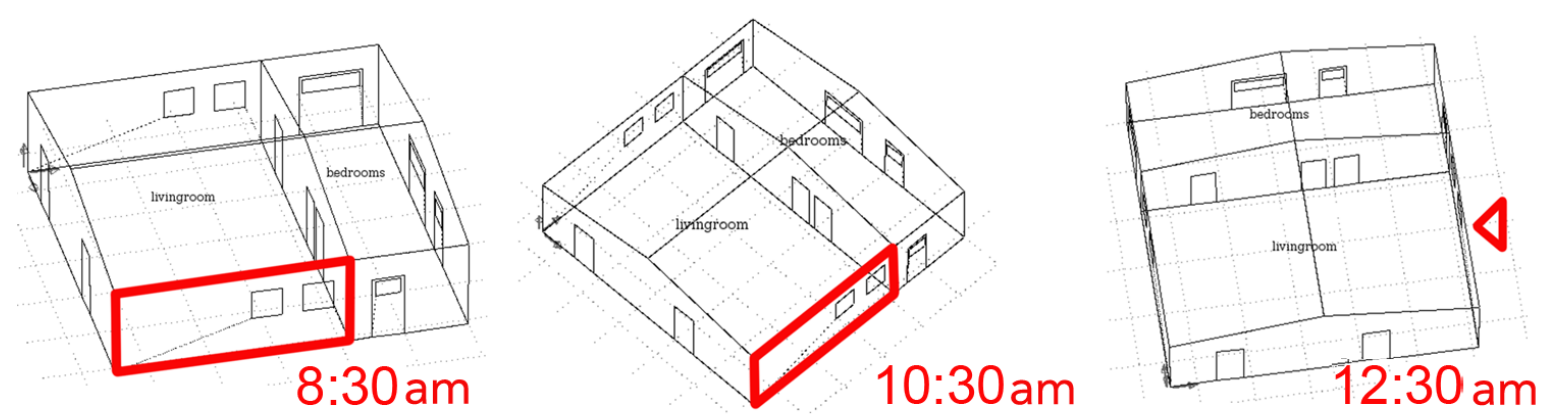

Figure 5. ESP-r model views from the Sun (east facade, morning of 17 August).

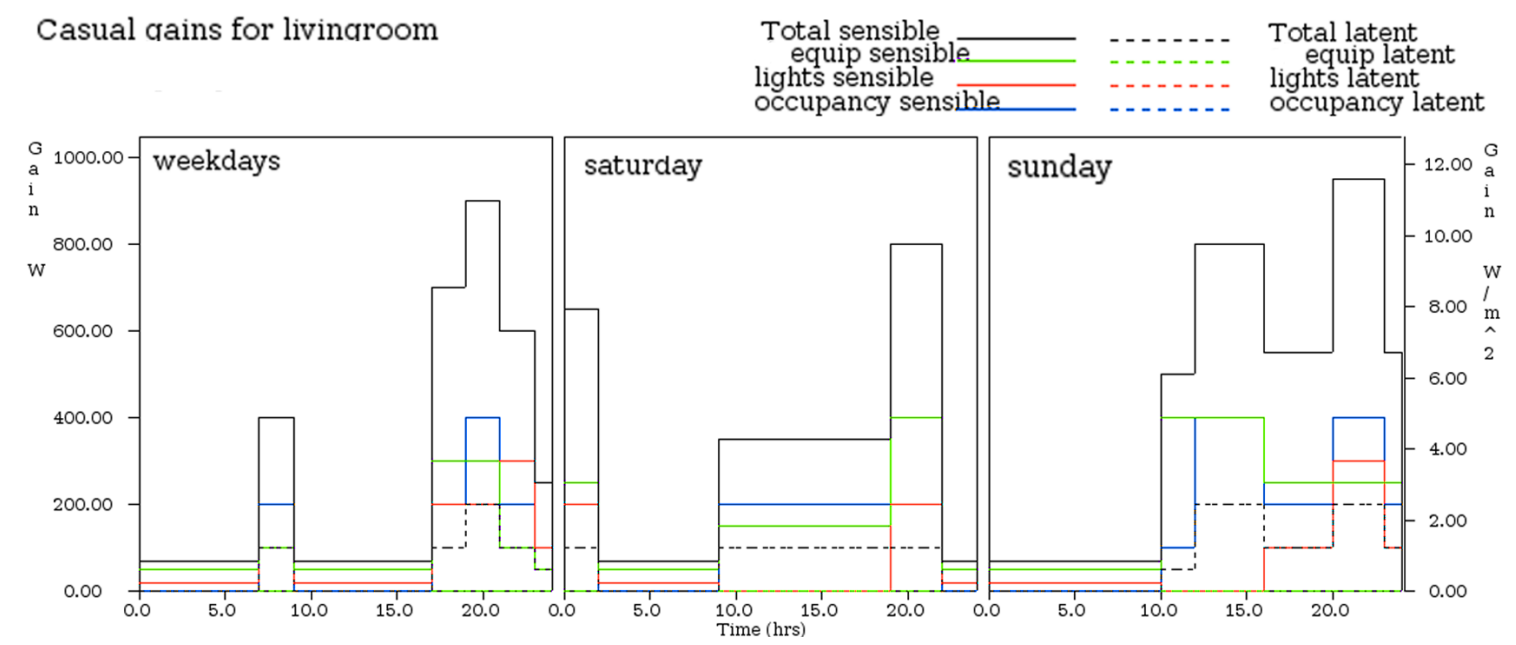

Figure 6. Building model in ESP-r: living room casual heat gains. 


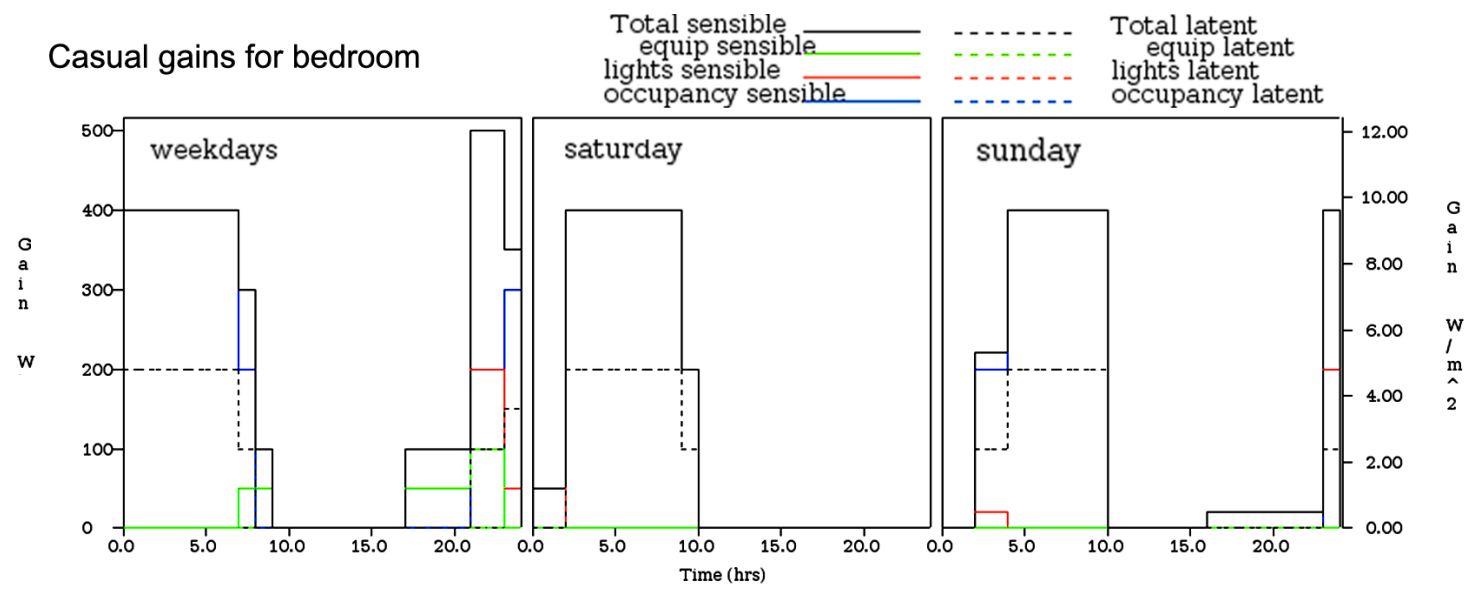

Figure 7. Building model in ESP-r: bedroom casual heat gains.

\subsubsection{Materials}

Seven high-performance envelopes, suitable to be used in new buildings, were investigated: two classical constructions of an externally-insulated wall and a sandwich wall and three light structures are adopted from the work of Leccese and Tuoni [17]. In addition, one ecological solution built with local materials (straw bales and earth) and a fictitious ultralight wall with EPSonly that is used as a reference. The proposed materials are intentionally all well known and commonly available in the construction market. Advanced solutions, such as phase change materials (PCM) or vacuum insulation panels (VIP), although very interesting, have not been included in this study in order to keep the attention on the design process rather than focusing on a particular technology.

The following nomenclature is used to identify the envelopes:

- A: external insulation (PTC)

- $\quad$ B: sandwich type (PTS)

- $\quad$ C: Light Wall 1 (PL1)

- D: straw bale and earth (STRB)

- $\quad$ E: Light Wall 2 (PL2)

- $\quad$ F: Light Wall 3 (PL3)

- G: EPS ultralight wall (PL4) (reference wall)

Each type is detailed in Appendix A, where the following features of each layer are specified:

- layer number

- material type

- thickness $(\mathrm{mm})$

- $\operatorname{density}\left(\mathrm{kg} / \mathrm{m}^{3}\right)$

- $\quad$ conductivity $(\mathrm{W} / \mathrm{mK})$

- $\quad$ heat capacity $c_{p}(\mathrm{~J} / \mathrm{kgK})$

- coefficients of IR emissivity $\varepsilon$ and solar absorption $\alpha$

\section{Results}

Seven different wall types are investigated, as described in Section 2.3.3, and ranked according to each method of Section 2 in order to support the design process. The outputs provided by the building energy and exergy analysis were compared for the case study and are presented in Sections 3.1 and 3.2, respectively. Some data from the dynamic energy analysis underpinning the exergy calculations are finally reported in Section 3.3 in order to provide a deeper insight into the envelope behaviour. 


\subsection{Energy Analysis}

The energy analysis is conducted on the basis of the methods described in Section 2.1. The following envelope indicators, illustrated in Figure 8, the left part of Figure 9 and in Table 1, are commonly used in the design process:

- $\quad$ U-value $\left(U\left(\mathrm{~W} / \mathrm{m}^{2} \mathrm{~K}\right)\right)$

- decrement factor $(f)$ and time lag $(\tau(h))$

- $\quad$ mass per area $\left(M_{a}\left(\mathrm{~kg} / \mathrm{m}^{2}\right)\right)$ and static thermal capacity $\left(C_{t, a}\left(\mathrm{KJ} / \mathrm{m}^{2} \mathrm{~K}\right)\right)$.

The following parameters, which are observable in the right part of Figure 9 and also reported in Table 1, are rarely adopted in practice and thus will be used in this study only for additional discussion in Section 4:

- $\quad$ indoor admittance modulus $\left(Y_{i i}\right.$ modulus $\left.\left(\mathrm{W} / \mathrm{m}^{2} \mathrm{~K}\right)\right)$ and phase $\left(Y_{i i}\right.$ phase $\left.(\mathrm{h})\right)$.

The U-value has a greater significance, for the climate of the case study, during the winter period, when the building behaviour can be reasonably approximated with a static model. The U-value is therefore the main factor used to preselect the investigated envelopes. While some of the selected seven envelopes (described in Section 2) have a better U-value than others, all seven envelopes of this study allow the building to achieve a high winter performance for the considered location. The energy ranking related to the summer behaviour is then produced only in terms of the decrement factor $f$ and the time lag $\tau$, as per common design practice.

The comparison of the different envelope types based on decrement factor $f$ and time lag $\tau$ indicates a five-layer light structure (label F) as the best performing (i.e., lowest decrement factor $f=0.17$ and large time lag $\tau=11 \mathrm{~h}$, in Figure 8) among the classic solutions, A, B, C, E, F (as listed in Appendix A) and the unconventional solution, $\mathrm{D}$, which is composed of straw bales and earth, as the best overall solution (at the price of a considerable wall thickness). The envelope $C$ and the fictitious wall $\mathrm{G}$ have a performance very similar to $\mathrm{F}$, with a higher decrement factor $(f=0.196$ and $f=0.200$, respectively) and a higher time lag ( $\tau \approx 12 \mathrm{~h}$ and $\tau \approx 14 \mathrm{~h}$ ). Since the time lags are all high enough to imply an effective deferment of the diurnal outdoor temperature waves to the night, the decrement factor can be considered as more important during the ranking of these envelope types than the time lag, and therefore, $\mathrm{F}$ is ranked as a better solution in terms of energy. It is worthwhile to mention that $\mathrm{G}$ is a fictitious structure used as a reference, and therefore, the real comparison is between $\mathrm{F}$ and $\mathrm{C}$.
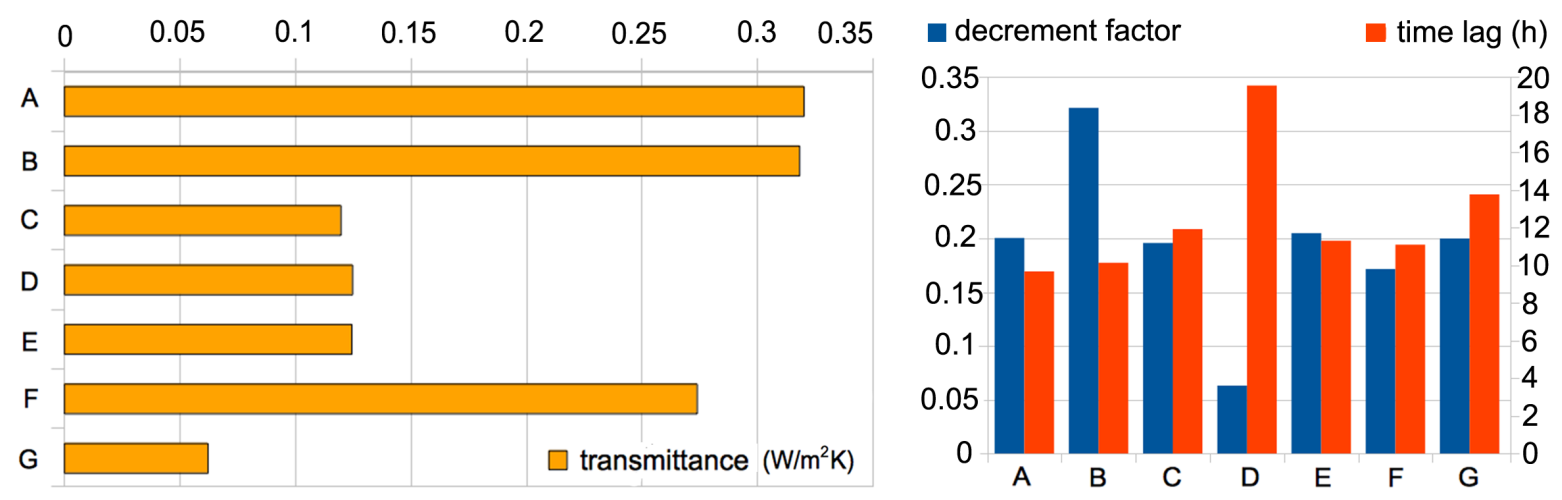

Figure 8. Energy analysis results. Left: thermal transmittance. Right: decrement factor and time lag. 


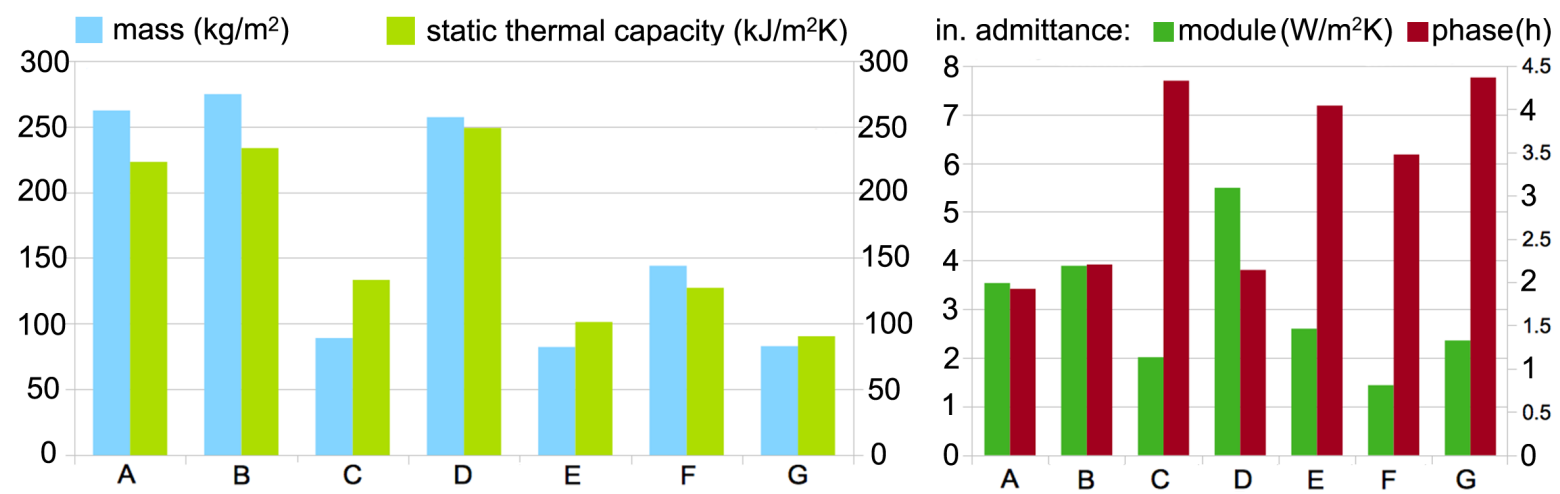

Figure 9. Energy analysis. Left: mass and thermal capacity. Right: indoor admittance (mod, phase).

Table 1. Energy performance and ranking of the investigated wall types.

\begin{tabular}{ccccccccc}
\hline $\begin{array}{c}\text { Wall } \\
\text { Name }\end{array}$ & $\begin{array}{c}\mathbf{U} \\
\left(\mathbf{W} / \mathbf{m}^{2} \mathbf{K}\right)\end{array}$ & $f$ & $\begin{array}{c}\tau \\
\mathbf{( h )}\end{array}$ & $\begin{array}{c}\boldsymbol{M}_{\boldsymbol{a}} \\
\left(\mathbf{k g} / \mathbf{m}^{\mathbf{2}}\right)\end{array}$ & $\begin{array}{c}\boldsymbol{C}_{t, \boldsymbol{a}} \\
\left(\mathbf{k J} / \mathbf{m}^{\mathbf{2}} \mathbf{K}\right)\end{array}$ & $\begin{array}{c}\boldsymbol{Y}_{i i} \mathbf{M o d} \\
\left(\mathbf{W} / \mathbf{m}^{\mathbf{2}} \mathbf{K}\right)\end{array}$ & $\begin{array}{c}\boldsymbol{Y}_{i i} \mathbf{p h} \\
\mathbf{( h )}\end{array}$ & $\begin{array}{c}\text { Energy } \\
\text { Ranking }\end{array}$ \\
\hline $\mathrm{A}$ & 0.320 & 0.200 & 9.67 & 262 & 223 & 3.54 & 1.92 & 5 \\
$\mathrm{~B}$ & 0.318 & 0.321 & 10.14 & 275 & 234 & 3.89 & 2.20 & 7 \\
$\mathrm{C}$ & 0.121 & 0.196 & 11.93 & 89 & 133 & 2.01 & 4.33 & 3 \\
$\mathrm{D}$ & 0.126 & 0.063 & 19.55 & 257 & 249 & 5.49 & 2.14 & 1 \\
E & 0.124 & 0.205 & 11.31 & 82 & 101 & 2.60 & 4.02 & 6 \\
F & 0.274 & 0.171 & 11.10 & 144 & 127 & 1.44 & 3.47 & 2 \\
G & 0.062 & 0.200 & 13.77 & 83 & 90 & 2.36 & 4.37 & 4 \\
\hline
\end{tabular}

\subsection{Exergy Analysis}

The theoretical exergy analysis illustrated in Section 2.2 suggests maximising the useful exergy extracted from the surrounding environment during a daily cycle in order to reduce power input requirements. In the particular case of the summer performance of a building located in a Mediterranean climate, this optimisation can be carried out by maximising the objective Function (11) over a typical summer day, in order to obtain the optimum design for the selected passive strategy (in this case, nocturnal free cooling).

The objective function suggests increasing the ventilation rate when the external temperatures are below the comfort set-point, by an amount dependent on the quality factor (exergy) of the external air. Dynamic calculations are therefore performed in free-floating mode at increasing rates of nocturnal ventilation from $0.5-10$ air changes per hour $(\mathrm{ACH})$. The different types of envelope sections are then quantitatively compared through the objective function (11), as reported in Figure 10 and Table 2.

The exergy ranking (in Table 2) differs from the energy ranking (Table 1 of Section 3.1). Type D (straw bale and rammed earth, as detailed in Section 2) is highlighted as the most suitable for cool-exergy storage through night ventilation, followed by the sandwich solution, B, whilst the initially high-energy-performing wall, $\mathrm{F}$, is found to be the worst selection in terms of exergy storage (together with the fictitious solution, G, which has the lowest objective function value). 


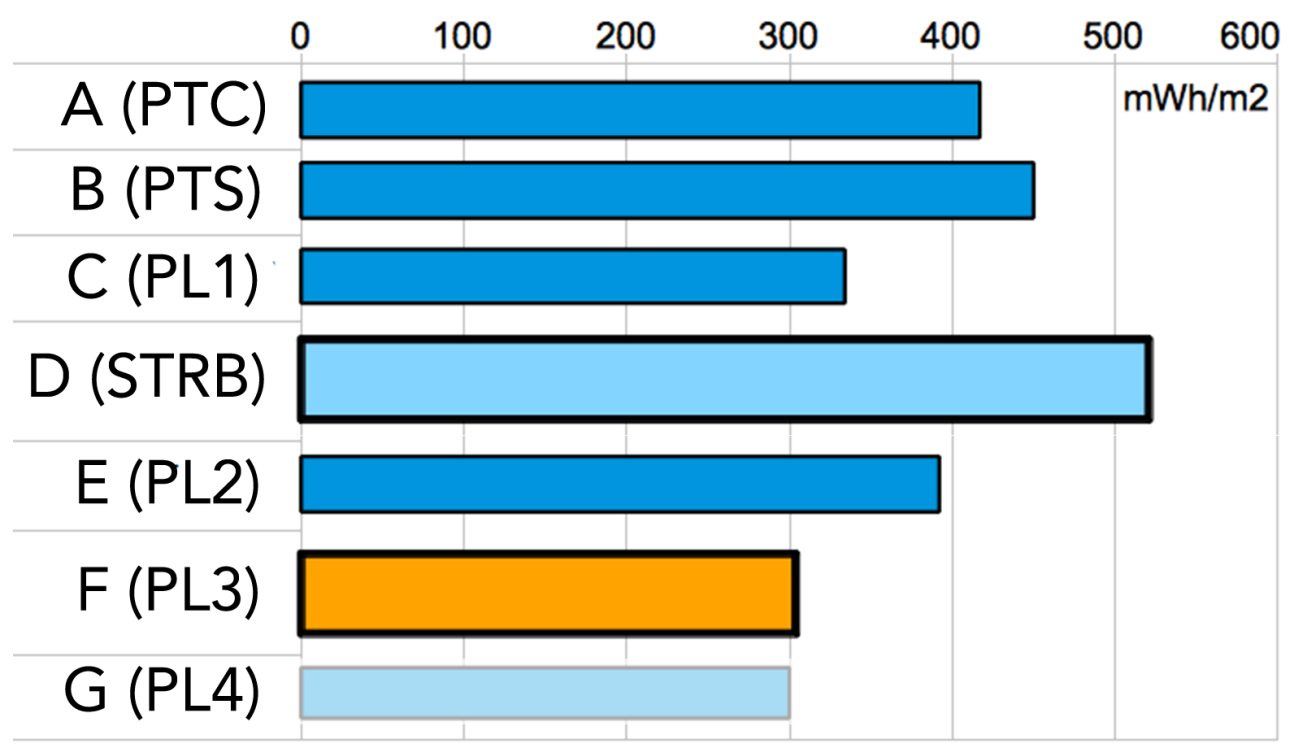

Figure 10. Objective function (10 air changes per hour (ACH), 17/08).

Table 2. Numerical values of Figure 10.

\begin{tabular}{ccc}
\hline Wall Name & Objective Function $\left(\mathbf{m W h} / \mathbf{m}^{\mathbf{2}}\right)$ & Exergy Ranking \\
\hline A & 417 & 3 \\
B & 450 & 2 \\
C & 334 & 5 \\
D & 521 & 1 \\
E & 392 & 4 \\
F & 304 & 6 \\
G & 300 & 7 \\
\hline
\end{tabular}

\subsection{Dynamic Energy Analysis Underpinning the Exergy Calculations}

The values of maximum indoor operative temperatures, derived from the ESP-r simulations, but not directly used for ranking, are shown in Figure 11 and Table 3. Asymptotic values are calculated, as a reference, by imposing high rates of ventilation (100 ACH; the minimum is reported in Figure 11).

Table 3. Max zone operative temperature values (17 August).

\begin{tabular}{cccc}
\hline Wall Type & $\mathbf{T}\left({ }^{\circ} \mathbf{C}\right) @ \mathbf{0 . 5} \mathbf{A C H}$ & $\mathbf{T}\left({ }^{\circ} \mathbf{C}\right) @ \mathbf{5 ~ A C H}$ & T $\left({ }^{\circ} \mathbf{C}\right) @ \mathbf{1 0} \mathbf{A C H}$ \\
\hline A & 28.92 & 27.68 & 27.40 \\
B & 28.91 & 27.63 & 27.35 \\
C & 29.39 & 28.11 & 27.86 \\
D & 28.99 & 27.42 & 27.07 \\
E & 29.42 & 27.68 & 27.37 \\
F & 29.37 & 28.28 & 28.05 \\
G & 29.21 & 27.94 & 27.68 \\
\hline
\end{tabular}




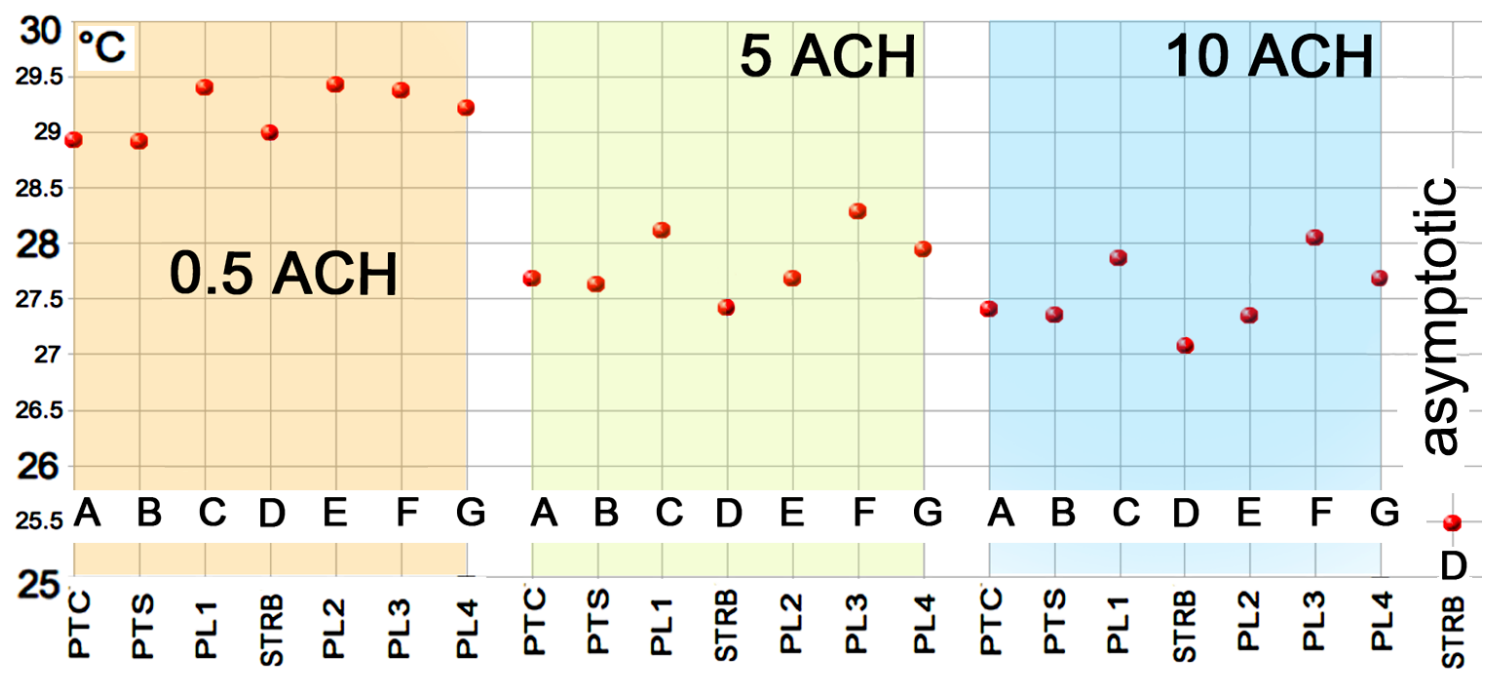

Figure 11. Maximum zone operative Tin free-floating mode at different $\mathrm{ACH}$ (17 August).

\section{Discussion}

The energy analysis based on decrement factor $f$ and time lag $\tau$ suggests Solutions D, F and C as the first, second and third best options for the case study. In a standard design procedure, one of these high-performance walls would be selected on the basis of other important considerations; for example, $\mathrm{F}$ could be chosen instead of $\mathrm{D}$ if the wall thickness is a concern. Solution $\mathrm{B}$ would be discarded because it has the worst performance in terms of decrement factor and time lag (as shown in Figure 8). However, the energy performance indicators classically used in the basic design process (U-value, $f$ and $\tau$ ) do not consider the impact of internal loads, which is often relevant. More advanced energy-performance indicators, such as the thermal admittance $Y_{i i}$, are rarely used and are difficult to interpret. In the case study of this paper, it is actually possible to understand from the indoor admittance shown in Figure 9 that Type $\mathrm{F}$ is characterised by a poor storage response to internal loads, since the surface flux caused by an indoor temperature variation is the lowest $\left(\approx 1.5 \mathrm{~W} / \mathrm{m}^{2} \mathrm{~K}\right)$, as opposed to those for Envelopes $\mathrm{D}$ and $\mathrm{B}\left(\approx 5.5\right.$ and $4 \mathrm{~W} / \mathrm{m}^{2} \mathrm{~K}$, respectively). However, the admittance value itself does not provide an overall quantitative ranking index for the specific case because the relative impact of the different energy indicators (U-value, $f, \tau$ and $Y_{i i}$ ) is not known and could not be used for suggesting possible operational strategies, such as the increase of nocturnal ventilation.

On the other hand, when considering the exergy results, the surrounding environment is analysed in search of useful interactions (second step of the design process described in Section 2.2.2). The definition of the reference state as a constant value that is equal to the upper limit of comfort ( $26^{\circ} \mathrm{C}$ in this case) implies that everything at a lower temperature is seen as a potential source of environmental "cool" exergy $B_{\text {env }}$ that can contribute to indoor comfort. The simplest choice for increasing the term $B_{\text {env }}$ of the exergy balance in the climate of our case study is to exploit the low temperatures of the night through nocturnal natural ventilation. We therefore carry out an investigation of different rates of night ventilation, a step that is not normally included in standard practice. The envelope reaction is explored through the objective Function (11), and the resulting exergy ranking is substantially different from the one obtained with energy considerations (apart from Envelope D), because the different construction types have different exergy storage capacities.

Finally, the comparison of the maximum indoor operative temperatures (in the living-room zone) from the dynamic energy simulations confirms that the increased nocturnal ventilation impacts significantly the free-floating building behaviour and, as indicated by the exergy analysis, that Envelopes D, B and A are capable, when combined with nocturnal natural ventilation, of maintaining the indoor conditions within or close to the comfort ranges. The graph in Figure 11 shows that the transition from $0.5 \mathrm{ACH}-5 \mathrm{ACH}$ has the greatest impact on reducing indoor temperatures in summer, 
and the benefits of higher rates decrease when passing from $5 \mathrm{ACH}-10 \mathrm{ACH}$. Asymptotic values for the best envelope option, D, show that, for the particular case study, the envelope could store enough cool exergy to maintain comfort, if enhanced exchanges with the outdoor air were implemented. The main results are summarised in Table 4.

Table 4. Summary of the results.

\begin{tabular}{cccccc}
\hline Wall Type & Energy Ranking & Exergy Ranking & $\begin{array}{c}\text { Max in.T }\left({ }^{\circ} \mathbf{C}\right) \\
\text { @ 0.5 ACH }\end{array}$ & $\begin{array}{c}\text { Max in. T }\left({ }^{\circ} \mathbf{C}\right) \\
\text { @ 5 ACH }\end{array}$ & $\begin{array}{c}\text { Max in. T }\left({ }^{\circ} \mathbf{C}\right) \\
\text { @ 10 ACH }\end{array}$ \\
\hline A & 5 & 3 & 28.92 & 27.68 & 27.40 \\
B & 7 & 2 & 28.91 & 27.63 & 27.35 \\
C & 3 & 5 & 29.39 & 28.11 & 27.86 \\
D & 1 & 1 & 28.99 & 27.42 & 27.07 \\
E & 6 & 4 & 29.42 & 27.68 & 27.37 \\
F & 2 & 6 & 29.37 & 28.28 & 28.05 \\
G & 4 & 7 & 29.21 & 27.94 & 27.68 \\
\hline
\end{tabular}

\section{Conclusions}

This research, although very limited in scope, suggests that exergy could constitute a sound theoretical framework for a direct quantitative comparison of different storage strategies for the building envelope. Even if some conclusions can be achieved also by means of a careful analysis of the dynamic energy simulation data, especially when passive strategies are examined before the plant design, exergy considerations guide the designer directly towards the most relevant phenomena for a successful interaction with the surroundings. Therefore, properly-developed exergy indices could be a valid support in the building design process, especially where resilience and thermal autonomy represent the main targets.

In the presented case study, the exergy analysis ranking is different from the classical energy ranking adopted in the early stages of design because the investigated walls react differently to the increased ventilation rate, as some have a greater exergy storage capability than others. The nocturnal ventilation, which is selected as a simple method of exergy extraction from the environment, has a significant impact on the resultant zone temperatures and can thus be considered an effective strategy for maintaining indoor comfort when combined with a suitable envelope.

Exergy quantifies energy quality through a reference environment and thus provides an overall view and useful insight to optimise the building behaviour on a daily or seasonal basis rather than instantaneous demands. Three iterative design steps can reduce the need for a power input:

1. envelope demand reduction through energy conservation measures

2. exergy extraction from the surrounding environment

3. power input and irreversibility optimization

In the second step, the focus of this research, exergy analysis constitutes an effective guidance for investigating and enhancing useful interactions between the building and the environment.

There are still some major obstacles to the development and dissemination of dynamic building exergy analysis. First, the reference state definition is highly controversial, and additional discussion is needed to reach a consensus on this topic. In addition, the theoretical approach underpinning the exergy analysis is more complex than the classical energy design process: a dynamic energy simulation is required to produce dynamic exergy results, and thus, the exergy calculations cannot be performed as an alternative, but constitute a further step. Furthermore, the lack of exergy simulation tools, especially dynamic and open-source, surely makes the advancements in this field even more complex. However, two considerations could justify the research effort in this field: dynamic exergy assessments can provide a very specific guidance focused on enhancing positive interactions between 
the building and its outdoor environment and do not require more inputs than a detailed dynamic energy simulation.

Acknowledgments: The authors thank the Engineering and Physical Sciences Research Council U.K. (EPSRC, Grant No. 1586601) and the Building Research Establishment (BRE) for the financial support, as well as the anonymous reviewers for their extremely valuable contribution.

Author Contributions: Valentina Bonetti developed the study conception and design, produced the mathematical and simulation models, analysed and interpreted the results, drafted the manuscript; Georgios Kokogiannakis contributed to every stage with critical revisions.

Conflicts of Interest: The authors declare no conflict of interest. The founding sponsors had no role in the design of the study; in the collection, analyses or interpretation of data; in the writing of the manuscript; nor in the decision to publish the results.

\section{Abbreviations}

The following abbreviations are used in this manuscript:

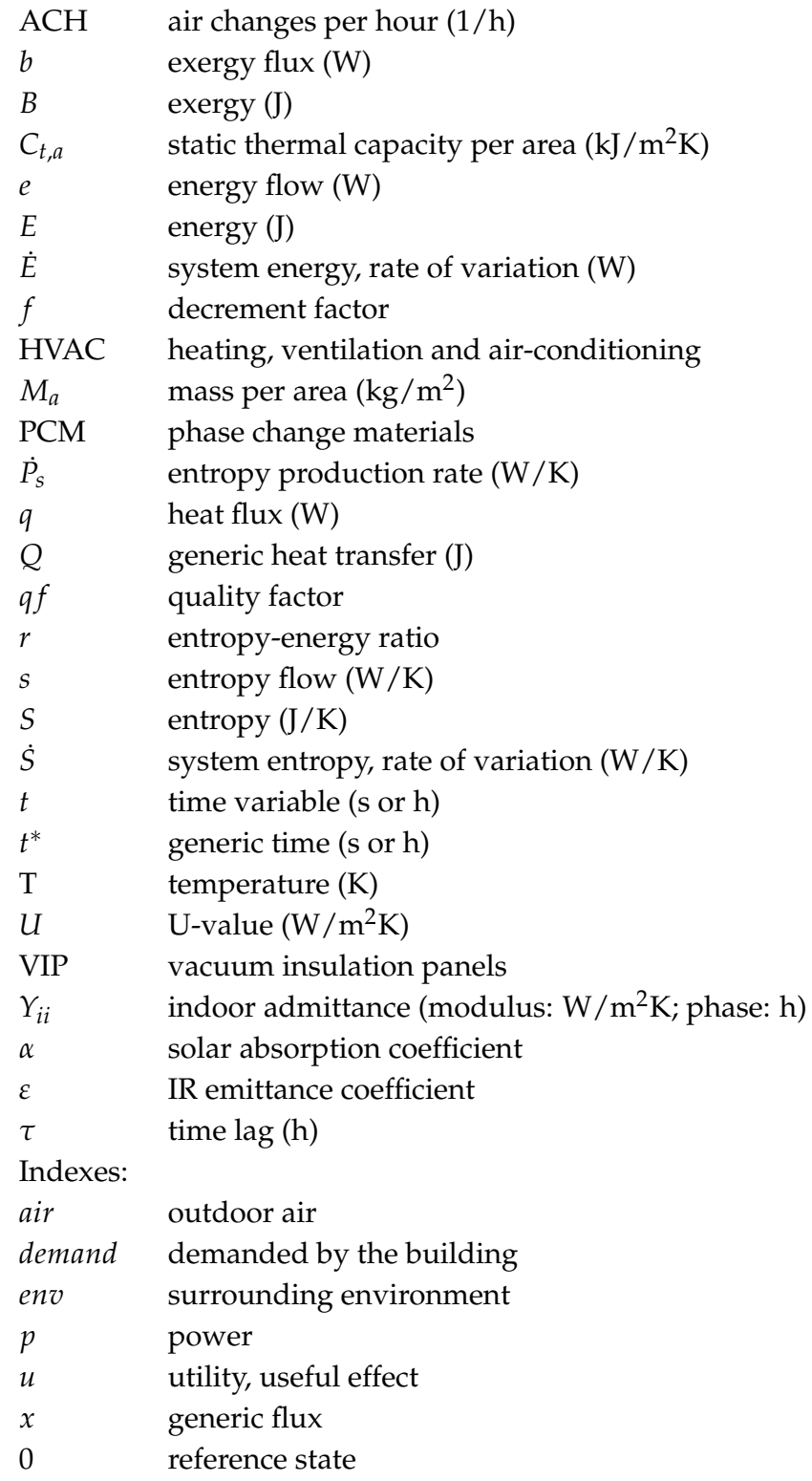




\section{Appendix A}

Details of the investigated wall constructions are reported in the tables of this section.

Table A1. Case A: externally-insulated wall, "PTC" (Layer 1 is outdoors). Thickness: 350 mm.

\begin{tabular}{ccccccc}
\hline Layer No. & Material & Thickness $\mathbf{( m m )}$ & $\begin{array}{c}\text { Density } \\
\left(\mathbf{k g} / \mathbf{m}^{3}\right)\end{array}$ & $\begin{array}{c}\text { Conductivity } \\
\mathbf{( W / m K )}\end{array}$ & $\begin{array}{c}\boldsymbol{c}_{\boldsymbol{p}} \\
(\mathbf{J} / \mathbf{k g K})\end{array}$ & $\varepsilon-\boldsymbol{\varepsilon}$ \\
\hline 1 & plaster & 10 & 1600 & 1.000 & 880 & $0.91-0.26$ \\
2 & exp.polystyrene & 80 & 35 & 0.034 & 1400 & $0.90-0.30$ \\
3 & brick & 250 & 910 & 0.430 & 840 & $0.90-0.90$ \\
4 & plaster & 10 & 1600 & 1.000 & 880 & $0.91-0.26$ \\
\hline
\end{tabular}

Table A2. Case B: sandwich wall, "PTS" (Layer 1 is outdoors). Thickness: $340 \mathrm{~mm}$.

\begin{tabular}{ccccccc}
\hline Layer No. & Material & Thickness $(\mathbf{m m})$ & $\begin{array}{c}\text { Density } \\
\left(\mathbf{k g} / \mathbf{m}^{\mathbf{3}}\right)\end{array}$ & $\begin{array}{c}\text { Conductivity } \\
\mathbf{( W / m K )}\end{array}$ & $\begin{array}{c}c_{p} \\
(\mathbf{J} / \mathbf{k g K})\end{array}$ & $\varepsilon-\boldsymbol{\alpha}$ \\
\hline 1 & plaster & 10 & 1600 & 1.000 & 880 & $0.91-0.26$ \\
2 & brick (2) & 120 & 1000 & 0.400 & 840 & $0.90-0.90$ \\
3 & exp. polystyrene & 80 & 35 & 0.034 & 1400 & $0.90-0.30$ \\
4 & brick (2) & 120 & 1000 & 0.400 & 840 & $0.90-0.90$ \\
5 & plaster & 10 & 1600 & 1.000 & 880 & $0.91-0.26$ \\
\hline
\end{tabular}

Table A3. Case C: light wall with 8 layers, "PL1" (Layer 1 is outdoors). Thickness: 382 mm.

\begin{tabular}{ccccccc}
\hline Layer No. & Material & Thickness $(\mathbf{m m})$ & $\begin{array}{c}\text { Density } \\
\left(\mathbf{k g} / \mathbf{m}^{3}\right)\end{array}$ & $\begin{array}{c}\text { Conductivity } \\
(\mathbf{W} / \mathbf{m K})\end{array}$ & $\begin{array}{c}c_{p} \\
(\mathbf{J} / \mathbf{k g K})\end{array}$ & $\varepsilon-\alpha$ \\
\hline 1 & wood fibre & 15 & 1400 & 0.200 & 1600 & $0.90-0.50$ \\
2 & air gap & 40 & - & - & - & - \\
3 & OSB & 20 & 600 & 0.160 & 1700 & $0.90-0.70$ \\
4 & rock wool & 100 & 80 & 0.035 & 1000 & $0.90-0.60$ \\
5 & OSB & 20 & 600 & 0.160 & 1700 & $0.90-0.70$ \\
6 & exp. polystyrene & 160 & 35 & 0.034 & 1400 & $0.90-0.30$ \\
7 & OSB & 15 & 600 & 0.160 & 1700 & $0.90-0.70$ \\
8 & gypsum & 12.5 & 1000 & 0.470 & 1000 & $0.91-0.22$ \\
\hline
\end{tabular}

Table A4. Case D: straw bales and earth wall, “STRB” (Layer 1 is outdoors). Thickness: 570 mm.

\begin{tabular}{ccccccc}
\hline Layer No. & Material & Thickness $(\mathbf{m m})$ & $\begin{array}{c}\text { Density } \\
\left(\mathbf{k g} / \mathbf{m}^{\mathbf{3}}\right)\end{array}$ & $\begin{array}{c}\text { Conductivity } \\
(\mathbf{W} / \mathbf{m K})\end{array}$ & $\begin{array}{c}c_{p} \\
(\mathbf{J} / \mathbf{k g K})\end{array}$ & $\varepsilon-\boldsymbol{\varepsilon}$ \\
\hline 1 & earth plaster & 30 & 1400 & 0.600 & 850 & $0.90-0.90$ \\
2 & straw & 460 & 120 & 0.060 & 1400 & $0.90-0.90$ \\
3 & earth & 80 & 2000 & 1.50 & 850 & $0.90-0.90$ \\
\hline
\end{tabular}


Table A5. Case E: light wall with 7 layers, "PL2" (Layer 1 is outdoors). Thickness: $428 \mathrm{~mm}$.

\begin{tabular}{ccccccc}
\hline Layer No. & Material & Thickness $(\mathbf{m m})$ & $\begin{array}{c}\text { Density } \\
\mathbf{( k g / \mathbf { m } ^ { 3 } )}\end{array}$ & $\begin{array}{c}\text { Conductivity } \\
(\mathbf{W} / \mathbf{m K})\end{array}$ & $\begin{array}{c}\boldsymbol{c}_{\boldsymbol{p}} \\
\mathbf{( J / k g K )}\end{array}$ & $\varepsilon-\boldsymbol{\varepsilon}$ \\
\hline 1 & composite & 30 & 550 & 0.090 & 1400 & $0.90-0.70$ \\
2 & exp. polystyrene & 60 & 35 & 0.034 & 1400 & $0.90-0.30$ \\
3 & mineral wood & 50 & 360 & 0.090 & 1550 & $0.90-0.70$ \\
4 & exp. polystyrene & 120 & 35 & 0.034 & 1400 & $0.90-0.30$ \\
5 & rock wool & 50 & 80 & 0.035 & 1000 & $0.90-0.60$ \\
6 & air gap & 80 & - & - & - & - \\
7 & gypsum & 37.5 & 1000 & 0.470 & 1000 & $0.91-0.22$ \\
\hline
\end{tabular}

Table A6. Case F: light wall with 5 layers, “PL3” (Layer 1 is outdoors). Thickness: 300 mm.

\begin{tabular}{ccccccc}
\hline Layer No. & Material & Thickness $(\mathbf{m m})$ & $\begin{array}{c}\text { Density } \\
\mathbf{( k g / \mathbf { m } ^ { 3 } )}\end{array}$ & $\begin{array}{c}\text { Conductivity } \\
\mathbf{( W / m K )}\end{array}$ & $\begin{array}{c}c_{p} \\
(\mathbf{J} / \mathbf{k g K})\end{array}$ & $\varepsilon-\boldsymbol{c}$ \\
\hline 1 & plaster & 10 & 1600 & 0.800 & 1000 & $0.91-0.26$ \\
2 & exp. polystyrene & 300 & 35 & 0.034 & 1400 & $0.90-0.30$ \\
3 & cellular concrete & 220 & 500 & 0.130 & 840 & $0.90-0.70$ \\
4 & exp. polystyrene & 300 & 35 & 0.034 & 1400 & $0.90-0.30$ \\
5 & plaster & 10 & 1600 & 0.800 & 1000 & $0.91-0.26$ \\
\hline
\end{tabular}

Table A7. Case G: ultralight wall, “PL4” (Layer 1 is outdoors). Thickness: 580 mm.

\begin{tabular}{ccccccc}
\hline Layer No. & Material & Thickness $(\mathbf{m m})$ & $\begin{array}{c}\text { Density } \\
\left(\mathbf{k g} / \mathbf{m}^{\mathbf{3}}\right)\end{array}$ & $\begin{array}{c}\text { Conductivity } \\
(\mathbf{W} / \mathbf{m K})\end{array}$ & $\begin{array}{c}\boldsymbol{c}_{\boldsymbol{p}} \\
(\mathbf{J} / \mathbf{k g K})\end{array}$ & $\varepsilon-\boldsymbol{\alpha}$ \\
\hline 1 & plaster & 20 & 1600 & 0.800 & 1000 & $0.91-0.26$ \\
2 & exp. polystyrene & 540 & 35 & 0.034 & 1400 & $0.90-0.30$ \\
3 & plaster & 20 & 1600 & 0.800 & 1000 & $0.91-0.26$ \\
\hline
\end{tabular}

\section{References}

1. McGovern, J.A. Exergy analysis-A different perspective on energy. Part 1: The concept of exergy. Proc. Inst. Mech. Eng. Part A J. Power Energy 1990, 204, 253-262.

2. Bejan, A.; Vadász, P.; Kröger, D.G. Energy and the Environment; Environmental Science and Technology Library; Springer: Dordrecht, The Netherlands, 1999; Volume 15, p. 265.

3. Schmidt, D.; Torio, H. ECBCS Annex 49: Low Exergy Systems for High-Performance Buildings and Communities; Technical Report; Fraunhofer IBP: Stuttgart, Germany, 2011.

4. Pons, M. On the reference state for exergy when ambient temperature fluctuates. Int. J. Thermodyn. 2009, 12, 113-121.

5. Davies, M.G. Optimum design of resistance and capacitance elements in modelling a sinusoidally excited building wall. Build. Environ. 1983, 18, 19-37.

6. Balaras, C.A. The role of thermal mass on the cooling load of buildings. An overview of computational methods. Energy Build. 1996, 24, 1-10.

7. Bojić, M.; Loveday, D. The influence on building thermal behavior of the insulation/masonry distribution in a three-layered construction. Energy Build. 1997, 26, 153-157.

8. Ma, P.; Wang, L.S.; Guo, N. Energy storage and heat extraction-From thermally activated building systems (TABS) to thermally homeostatic buildings. Renew. Sustain. Energy Rev. 2015, 45, 677-685.

9. The ESP-rCommunity. GitHub of the ESP-r Software. Available online: https://github.com/ESPrCommunity (accessed on 31 August 2016).

10. UNI Ente Nazionale Italiano di Unificazione. UNI EN ISO 13786; Technical Report; UNI: Milano, Italy, 2008. 
11. Torgal, F.P.; Mistretta, M.; Kaklauskas, A.; Granqvist, C.G.; Cabeza, L.F. Nearly Zero Energy Building Refurbishment. A Multidisciplinary Approach; Springer: London, UK, 2013; p. 181.

12. UNI Ente Nazionale Italiano di Unificazione. UNI/TS 11300-1; Technical Report; UNI: Milano, Italy, 2008.

13. Shukuya, M. Exergy Theory and Applications in the Built Environment; Springer: London, UK, 2013; p. 365.

14. Ursini Casalena, A. UNI EN ISO 13786 Spreadsheet, Version 2.2. Available online: http:/ / www.mygreenbuildings.org/2009/07/27/trasmittanza-termica-periodica-foglio-di-calcolo-excel-percalcolare-le-proprieta-termiche-dinamiche-di-un-componente-edilizio.html (accessed on 31 August 2016).

15. Clarke, J.A. Energy Simulation in Building Design; Butterworth-Heinemann: Oxford, UK, 2001; p. 362.

16. The ESP-rCommunity. ESP-r Database. Available online: https://github.com/AGeissler/myESP-rDatabases/blo b/master/climate/ita_rome_iwec.a (accessed on 1 November 2016).

17. Leccese, F.; Tuoni, G. Pareti leggere in edilizia. Guida all'impiego secondo la piu' recente normativa nazionale. Neo-Eubios 2008, 24, 14-21.

Sample Availability: Dynamic models for the ESP-r software are available from the authors.

(c) 2017 by the authors; licensee MDPI, Basel, Switzerland. This article is an open access article distributed under the terms and conditions of the Creative Commons Attribution (CC BY) license (http:/ / creativecommons.org/licenses/by/4.0/). 